It is considerations of this kind which make it so difficult to forecast the distant future with that degree of assurance adopted by some people with less knowledge of the metallurgical industries.

Apart from traditional ones, there are emerging a series of spectacular uses of metals which will control the whole of the future development in many fields of engineering. It is yet to be seen how far alloys based on the newer metals can be produced with properties which have hitherto been unobtainable, and a vast, indeed unlimited, field of metallurgical endeavour is thus opened out.

The big competitor with the metals would appear to be the plasties, particularly when suitably reinforced, and in some quarters there is the assumption that these will go on getting better and cheaper, while the metals themselves are becoming increasingly scarce. It is by no means certain that this somewhat superficial view can be justified. Given sufficient energy, imagination and enthusiasm on the part of the metallurgist, the metals, by improving the methods of extraction and fabrication, can also, perhaps, become cheaper ; and new alloys of better properties will most assuredly be developed. It is Mr. Bailey's forecast that the future of the use of metals, both for the more spectacular purposes of modern engineering, and for the older, traditional ones, is not only assured but also full of interest and, in places, definitely exciting.

\section{THE IMPACT OF ENGINEERING ON SOCIETY}

$\mathrm{F}^{\mathrm{o}}$ $\mathrm{R}$ the second Graham Clark Lecture, delivered to a joint meeting of the Institution of Civil Engineers, the Institution of Mechanical Engineers and the Institution of Electrical Engineers at the Institution of Mechanical Engineers on April 27, Sir Maurice Bowra, vice-chancellor of the University of Oxford, chose to speak on "The Impact of Engineer. ing on Society", pointing out that almost every society of which we know practised engineering to some degree. A considerable degree of civilization can be secured with a minimum of engineering; but a society which does not believe in engineering, or see its possibilities, is, as the failure of the Greek and Roman systems shows, unlikely to survive. Civilization is a sensitive plant, and its first duty is to look after itself. Sir Maurice suggests that the trouble with the Ancient World was that it never had any difficulty in finding men to do tasks which we assume should be done by machines, and the educated and governing classes accordingly never turned their minds to other, and better, ways of getting work done. That the Romans, like the Chinese, rejected machines in the last resort because their ruling classes were snobs is a social fact of first importance, and Sir Maurice proceeds to demonstrate its relevance to modern times, and to show how economic forces played an important part in securing recognition of the idea that machines can do much that men cannot do by themselves and in creating opportunities for the engineer.

This great change, however, has not been revolutionary in the political sense, although it has changed the whole appearance, and even the structure, of society. Engineering is not a political activity; it aims instead at the control and exploitation of natural resources to give a greater degree of human welfare, and it becomes political only when its existence is threatened by authority or when it is taken up by authority for its own sake. Indeod, within the limits of the social frame and national States within which the engineer works, his work has a strong stabilizing influence; and so far as engineers must share the blame for man's failure to evolve means for satisfying his desire for security and prosperity, it is for sins of omission rather than of commission.

In Sir Maurice's opinion, engineers have taken too modest a view of their own task and duties. More than any other branch of human activity, engineering provides an imaginative equivalent to war and has the advantage that it creates instead of destroying. Engineering, however, contributes much towards the drive towards uniformity and the destruction of that rich variety of experience which characterizes the great humanistic tradition; and it is a serious charge that the influence of engineering interferes with the variety of the individual self and shapes it to a uniform mould by imposing on it certain patterns through modern methods of indoctrination such as the press, cinema, wireless and television. Sir Maurice questions, however, whether such means will retain their ability to impose uniformity, and he also finds grounds for hope in the undeniable tendency of men to pursue the specially difficult task of thinking for themselves.

Engineering may in the end make it easier for thought to be free, and, while admitting that engineering tends to impose a standard of culture which lacks the variety and beauty of the old craftsmanship, Sir Maurice also sees no reason why a world that relies on machines more than on handicrafts should not produce objects as satisfying as those of the old craftsmen. Because they will give delight to a far greater number of people, a new kind of grace and charm may emerge, and if men really were to know what are the ends to which he would be able to turn Nature, he should be able to do on an ever extended scale what he has already begun to do with such imagination, devotion and skill.

\section{HEALTH HAZARDS IN THE COAL AND CHEMICAL INDUSTRIES}

$T$

WE first provincial meeting of the British Occupational Hygiene Society was held in the University Hall, Liverpool, during April 19-20. In his presidential address, Dr. C. G. Warner, dust suppression scientist of the South Western Division of the National Coal Board, spoke of the satisfactory progress of the Society, an indication that by practical activities it is fulfilling its aim of promoting the science of occupational hygiene. Dr. Warner went on to talk about the remarkably changed situation regarding pneumoconiosis in coal mines which has been occasioned, on one hand, by increased aware. ness of the disease and, on the other, by measures taken for suppressing airborne dust.

South Wales was formerly a bad area, and after 1943, when the legal definition of pneumoconiosis was relaxed, the rate of certificetion rose to a peak figure of $55 \cdot 6$ men per thousand employed; by 1947 it had fallen to $30 \cdot 8$. Meanwhile, in the rest of 